\title{
BETWEEN CONSUMPTION AND CONSERVATION: STUDYING THE SUSTAINABILITY OF BOTTLED WATER INDUSTRIES IN INDIA
}

\author{
Amam Jain \\ Modern School Barakhamba Road, New Delhi \\ DOI: 10.46609/IJSSER.2020.v05i10.003 URL: https://doi.org/10.46609/IJSSER.2020.v05i10.003
}

\begin{abstract}
The bottled water industry has seen tremendous growth globally, and especially in India. With increased tourism, increased growth of workplaces in urban areas, and a lack of access to clean tap water, there is an increase in the manufacturing and consumption of bottled water. The rise of the bottled water industry has raised several environmental concerns surrounding the use of single use plastics, the lack of sustainable manufacturing practices, and a lack of efforts of consumers to recycle. Although firms have undertaken CSR efforts to improve sustainability and access to water, activists critique the adequacy of such policies when the underlying manufacturing processes are not sustainable. This paper will examine the growth of the bottled water industry, and the perspectives surrounding sustainability of manufacturing and consumption. The paper will propose policy measures that can be undertaken to improve the market for water in such a way that the reliance on bottled water can in itself be reduced, in turn improving accessibility to water as a structural and systemic issue.
\end{abstract}

Keywords: CSR, Workplaces, Water, Industries, Revenue

\section{Introduction}

As water becomes more scarce in India, it is crucial to critically examine the bottled water industry in the country. The global bottled water industry was estimated to have a revenue of over $\$ 100$ billion worldwide, as per estimates in the year 2010 (Reset, n.d). The industry has continued to grow at a rapid pace globally, while an estimated three billion people in poor countries such as India do not have access to clean water and sanitation, and do not have access to water in their homes (Reset, n.d). As per estimates arrived at by the United Nations, about one-sixth of the global revenue of the bottled water industry can lead to a halving of the number of people who do not have access to clean water (Reset, n.d). 


\section{International Journal of Social Science and Economic Research}

ISSN: $2455-8834$

Volume:05, Issue:10 "October 2020"

In India, the packaged or bottled water industry is growing at a rate of about $15 \%$ every year (Singh and Shiva, 2019). This is driven by several factors such as an increase in urbanization and per capita spending, awareness of health risks associated with water that is not bottled, increase in tourism and active lifestyles, etc (Singh and Shiva, 2019). The major bottled water brands operating in India are Bisleri, Kinley, and Aquafina. However, several local brands as well as counterfeit brands have emerged in the market. Based on industry forecasts, the market in India is expected to have a worth of INR 403.06 billion by the end of the year 2023 (Singh and Shiva, 2019).

The increase in the consumption and production of bottled water is a cause for concern, due to its environmental impacts and effect on an already scarce water supply. There has been concern expressed by environmental activists that bottled water corporations are given free rein to mine local groundwater supplies. As a result, adverse effects are caused to the local populations and ecosystems, as well as a depletion of groundwater supplies. An example of this is the water shortage caused in 50 villages, due to groundwater mining by Coca-Cola for its Dasani brand of bottled water (Reset, n.d). On the other hand, the introduction and growth of the Corporate Social Responsibility regime in India has created some benefits to offset the environmental damage caused. For example, CSR initiatives by Nestle, one of the biggest distributors of bottled water, have led to the construction of drinking water facilities in schools, as well as water filtration systems in rural areas, cleaning water tanks, and supplying clean water to schools and households (Nestle, n.d). This reduces the dependence on single use plastics that are a primary concern with respect to bottled water, and promotes public health (Nestle, n.d).

This paper will further examine the scenario with regard to sustainability of the bottled water industry, and better methods to ensure that the industry moves away from single use plastics and incorporates more environmentally friendly methods. The paper will provide a critical overview of the CSR initiatives undertaken, and propose policy recommendations to incorporate technological advancements and social advocacy in the business of exploiting natural resources.

\section{Background}

With the amendments made to the Companies Act and the Corporate Social Responsibility Rules of 2014, corporations in India have been mandated to dedicate a percentage of their profits towards CSR activities. Companies such as Nestle, as mentioned above have implemented measures that have benefitted the communities in those areas. Hindustan Unilever Limited has initiated awareness efforts about sanitation and hygiene in rural areas (CSRBox, 2018). PepsiCo, one of the largest producers of bottled water as well as other beverages that are water intensive, claimed to have reached its goal of water efficiency by 2015 (Manku, 2015). The company has also claimed that through its CSR initiatives such as rain water harvesting, they have been able to 


\section{International Journal of Social Science and Economic Research}

ISSN: $2455-8834$

Volume:05, Issue:10 "October 2020"

conserve more water and recharge ground water more than they have consumed as a corporation (Manku, 2015). This equilibrium companies are seeking to achieve between input and output is known as 'water positivity'. Other companies such as United Breweries and Dabur have also continued to implement water saving and conservation initiatives under the ambit of their CSR budgets (Manku, 2015). Such initiatives can be broadly categorized into two categories- internal initiatives and external initiatives (Manku, 2015).

Internal initiatives involve making the process of manufacturing bottled water and other beverages more sustainable through recycling, reducing water consumption, harvesting water, and moving away from the manufacturing of single use plastics to more sustainable materials (Manku, 2015). External initiatives are similar to those mentioned above, such as working with government departments, and local communities to replenish groundwater and ensure access to clean drinking water (Manku, 2015). Initiatives can also be targeted towards the consumption of water and methods of water purification and packaging, to make that more sustainable, although these are typically consumer led and not helmed by the corporations themselves (Scientific American, 2020).

Changing consumer behaviour is difficult for the bottled water industry itself to control. However, by adopting sustainable practices in the manufacturing process, the act of consuming bottled water need not be as damaging to the environment as it is presently (Scientific American, 2020). That is the need of the hour, as statistics show that that 1.5 millions barrels of crude oil is used to make PET water bottles every year and 2.7 tonnes of plastic is used to bottle water (of which 86 percent ends up in the garbage or on the streets) (Reset, n.d). Therefore, it is also crucial to reduce our dependence on fossil fuels and the impact of this industry on fossil fuel consumption (Scientific American, 2020). The following section of the paper will elaborate further on the potential for such initiatives and the criticisms of the bottled water industry, in the Indian context.

\section{Discussion}

There is a global need and not only in India, to fuse social advocacy within business practices. This is the most important when the crux of the business is in utilizing and exploiting natural resources. Given that water is increasingly scarce, harnessing a social cause and combining the cause with the latest developments in sustainable technology is crucial to ensure that the future does not become catastrophic in the pursuit of profit. While CSR initiatives have bene traditionally viewed as a method to balance profit motives with sustainability, activists criticize the bottled water industry for its inadequacy in compensating for environmental damage caused (Manku, 2015). 


\section{International Journal of Social Science and Economic Research}

ISSN: $2455-8834$

Volume:05, Issue:10 "October 2020"

Activists are wary of large corporations claiming to be water positive, stating that there is no scientific foundation to this claim and it is not verified by any external and independent sources (Manku, 2015). In addition, water positivity can be assessed in reality on the ground, if the water that is extracted and the water that is conserved is within the same location. Activists are skeptical of this being the case, as the third parties that companies often hire to verify these claims do not assess the ground impact (Manku, 2015). In this regard, they believe that the only way to truly hold such companies accountable is not to rely solely on CSR initiatives that may or may not be implemented, but rather to change the economics of the industry fundamentally (Manku, 2015). This can be achieved by putting a price on the water that the industry uses, instead of allowing completely free access to groundwater, for example by digging bore wells. They argue that if the industrial use of water is priced accurately, it will automatically force the industry to become much more efficient and sustainable (Manku, 2015).

In addition, activists argue that most of the initiatives begun by the companies involved are only done so after protests by local communities, and motivated by the damage to their brand image and goodwill among consumers (Manku, 2015). On the other side of the debate are those who make the case for corporate involvement through CSR as a way to offset damage created, as they may be able to supplement in areas where governments do not have the resources or sufficient funds (Parekh et al, 2018). A study that mapped CSR interventions across the water value chain for companies on the NIFTY 50 revealed that states that are highly water stressed have a low or medium corporate presence with the exception of Maharashtra; it has the highest number of water interventions in the country (Parekh et al, 2018). A geographical analysis of corporate presence vis-a-vis the water stress level of states is an indicator of the need for corporate action in sustainability (Parekh, et al, 2018).

Companies must incorporate the latest technological developments in sustainability. For example, Nestle has been working closely with plastics processors to incorporate new technology and manufacture their bottles with recycled PET (Scientific American, 2020). The manufacturers shred the bottles, clean them and send them to a resin manufacturer, who will keep this material separate (Scientific American, 2020). The company then gets the crystalized PET back. Nestle's aim is to give rPET suppliers long-term contracts to provide incentives to invest in the technology (Scientific American, 2020). Other companies would benefit from incorporating such a long term model, as well. Companies could also take advantage of hightechnology sorting facilities, and futuristic plastic recyclers.

An important dynamic in the Indian social context is also the intersection between the economic conception and perception of water and a social and cultural notion of water. For example, a large part of the bottled water industry in India is also for religious purposes and sold to pilgrims, as well as shipped across the country (Swaminathan, 2016). The postal service is using its 


\section{International Journal of Social Science and Economic Research}

ISSN: $2455-8834$

Volume:05, Issue:10 "October 2020"

155,000 offices across India to deliver holy water from the Ganges, for far less than $\$ 1$ a bottle (Swaminathan, 2016). While the initiative has led to a decrease in pilgrims and consequently a reduction in the pollution of the river, this has been substituted by the manufacture and use of single use plastic, supplementing the already prevalent use of single use plastic for normal drinking water (Swaminathan, 2016). The Indian postal service reported that it had delivered 70,000 bottles of the holy water in the program's first few weeks (Swaminathan, 2016).

While technological advancement is crucial, changing consumer behaviour is an important aspect to improving the sustainability of the bottled water industry. The government and policy makers can introduce measures such as mandating recycling of plastic water bottles, installing bins in public areas specifically for recycling, and partnering with corporations to do so. With institutions like foundations invested in building an enabling ecosystem and companies leveraging their expertise to develop impactful solutions, the time is opportune for collaborative action across the water value chain (Parekh et al, 2018).

\section{Conclusion}

The future for the bottled water industry must entail a transformation into socially responsible water businesses. This can be achieved through public private partnerships, as well as the imposition of mandatory measures for both corporations and consumers to improve the sustainability of the bottled water manufacturing process as well as consumption. However, without undertaking structural solutions and viewing the issue as a systemic problem, the sustainability of either the industry or consumption cannot be improved.

The government in September 2019 asked manufacturers of packaged drinking water, like Pepsi and Coca Cola, to come up with alternative packaging (PTI, 2019). It is encouraging that the government recognized the need to change the materials to affordable and reliable options, rather than only rely on recycling as a measure (PTI, 2019).

Most consumers in the world who do not have access to clean water in their homes do not have the privilege of implementing common solutions suggested, such as drinking water from their taps, installing solar water heaters, or improving their water quality (Reset, n.d). We must consider the millions of consumers in the developing world without piped water, who are given no choice but to buy bottled alternatives at up to 10 times the price (Upchurch, 2013). Creating accessibility to water, and stable markets which do not damage the environment will involve establishing a fair price for water and reducing the inherent need to buy bottled water in the first instance (Upchurch, 2013).

Although the CSR regime is helpful in having corporations give back to the community and undertake beneficial initiatives, sustainability must not be about capitalizing on goodwill and 
International Journal of Social Science and Economic Research

ISSN: 2455-8834

Volume:05, Issue:10 "October 2020"

marketing. Although CSR initiatives are in early stages, there is a validity in the arguments of activists that it is not sufficient for companies to claim advancements that cannot be verified. Companies and the government must invest in a paradigm shift that incorporates the big meaningful changes that create a sustainable business regardless of consumer demand (Upchurch, 2013).

\section{References}

CSRbox, (2018), 'A List of 10 big CSR Projects in WASH Sector in India (FY 2016-17)', https://csrbox.org/India_CSR_news_A-List-of-10-big-CSR-Projects-in-WASH-Sector-in-India(FY-2016-17)_291

Manku, M, (2015), 'Water guzzling beverage firms are trying to give it back', Livemint, https://www.livemint.com/Companies/bYKcglaMr95kBM0eX3JwZM/Water-guzzling-beveragefirms-are-trying-to-give-it-back.html

Nestle, (n.d), 'Empowering Communities', Outlook: Corporate Social Responsibility, https://www.outlookindia.com/csr_2019/nestle.php

Parekh et al, (2018), 'Making The Case For Corporate Action In Water', Samhita, http://www.samhita.org/wp-content/uploads/2018/12/Making-a-case-for-corporate-action-inwater-Samhita-and-Ambuja-Cement-Foundation.pdf

PTI, (2019), 'Food ministry seeks alternatives for packaged drinking water', The Economic Times, https://economictimes.indiatimes.com/news/politics-and-nation/food-ministry-seeksalternatives-for-packaged-drinking-water/articleshow/71049611.cms?from $=\mathrm{mdr}$

Reset, (n.d), 'Avoiding Bottled Water', https://en.reset.org/act/avoid-bottled-water

Scientific American, (2020), 'A Crystal Clear Path To Sustainable Bottled Water', https://www.scientificamerican.com/custom-media/pictet/a-crystal-clear-path-to-sustainablebottled-water/

Singh, A, and Shiva, K, (2019), 'Current Scenario of Water Bottling Companies in India', FnBnews.com, http://fnbnews.com/Beverage/current-scenario-of-water-bottling-companies-inindia-53493

Swaminathan, K, (2016), 'Holy Water for Pilgrims, via the Mail', The New York Times, https://www.nytimes.com/2016/08/26/world/what-in-the-world/holy-water-at-home-in-india-apilgrimage- 
International Journal of Social Science and Economic Research

ISSN: 2455-8834

Volume:05, Issue:10 "October 2020"

alternative.html\#: :text=The $\% 20$ water $\% 20$ is $\% 20$ drawn $\% 20$ from,holding $\% 207 \% 20$ or $\% 2017 \% 2$ 0ounces.

Upchurch, L, (2013), 'Can bottled water ever really be sustainable?', The Guardian, https://www.theguardian.com/sustainable-business/can-bottled-water-be-sustainable 